\title{
The motivation to learn as a self-presentation tool among Swiss high school students: The moderating role of mastery goals' perceived social value on learning is
}

\author{
Annique Smeding a,*, Benoît Dompnier ${ }^{\mathrm{b}}$, Emanuele Meier ${ }^{\mathrm{b}}$, Céline Darnon ${ }^{\mathrm{c}, \mathrm{d}}$, \\ Bernard Baumberger ${ }^{\mathrm{e}}$, Fabrizio Butera ${ }^{\mathrm{b}}$ \\ a Savoie Mont Blanc University, France \\ ${ }^{\mathrm{b}}$ University of Lausanne, Switzerland \\ c Clermont University, France \\ d University Institute of France, France \\ e University of Teacher Education, State of Vaud, Switzerland
}

\section{A R T I C L E I N F O}

Article history:

Received 24 November 2014

Received in revised form 17 August 2015

Accepted 29 August 2015

\section{Keywords:}

Mastery goals

Learning

Individual differences in social value

High school

\begin{abstract}
A B S T R A C T
Although it has been assumed that the motivation to learn - or mastery goal endorsement - positively predicts learning achievement, most empirical findings fail to demonstrate this relationship. In the present research, conducted in a Swiss high school, we adopted a social value approach to test the hypothesis that adolescent students' mastery goals do in fact predict learning, but only if these goals are perceived as highly useful for scholarly success (high social utility), and are not endorsed as a means to be appreciated by the teachers (low social desirability), a finding that has previously been observed among college students and on teacher-graded achievement measures only. Results demonstrate that in spite of potential peculiarities of an adolescent population, individual differences in mastery goals' perceived social utility and desirability moderate the mastery goal endorsement-learning achievement relation. Findings are discussed with regard to both theory development and educational practice.
\end{abstract}

(c) 2015 Elsevier Inc. All rights reserved.

\section{Introduction}

Developing and sustaining adolescent students' motivation to learn represents an important educational challenge for teachers, parents, and policy-makers alike, as this motivation is assumed to foster learning and achievement (Ames, 1992; Dweck \& Leggett, 1988). Indeed, the motivation to learn has been shown to favor various positive outcomes related to learning, such as task interest, persistence after failure, help seeking, and cooperation (see for reviews Darnon, Dompnier, \& Poortvliet, 2012; Harackiewicz, Barron, Pintrich, Elliot, \& Thrash, 2002; Poortvliet \& Darnon, 2010; Senko, Hulleman, \& Harackiewicz, 2011). In achievement goal

\footnotetext{
ฟ We extend our gratitude to the high school's deans, teachers, and students who accepted to participate in this research. This research was supported by the Swiss National Science Foundation (Grant No. 100014_135607).

* Corresponding author at: LIP/PC2S, Université Savoie Mont Blanc, BP 1104, 73011 Chambéry cedex, France.

E-mail address: Annique.Smeding@univ-savoie.fr (A. Smeding).
}

research, motivation to learn, to progress, and to master tasks has been referred to as mastery - or learning - goals. ${ }^{1}$ These goals have generally been contrasted with performance goals, whose focus is on demonstrating competence as compared to others (Ames, 1992; Elliot, 1999; Nicholls, 1984).

In spite of the positive link between mastery goals (hereafter MG) and various achievement-related outcomes, the link with actual achievement remains a much debated issue (Senko et al., 2011). For instance, a review by Linnenbrink-Garcia, Tyson, and Patall (2008) indicated that only $40 \%$ of the relevant studies found evidence for a positive relation between MG and achievement. Findings from recent meta-analyses highlighted the overall small MG-achievement correlations (Huang, 2012; Hulleman, Schrager, Bodmann, \& Harackiewicz,

\footnotetext{
1 Mastery goals, as performance goals, have been further separated into masteryapproach (the motivation to learn) and mastery-avoidance goals (the motivation to avoid not to learn; Elliot \& McGregor, 2001). In this research we focus on mastery-approach goals, as they are the ones supposed to predict achievement (Elliot \& Murayama, 2008); for the sake of simplicity, we will then use the term mastery goals for mastery-approach goals.
} 
2010; Wirthwein, Sparfeldt, Pinquart, Wegerer, \& Steinmayr, 2013), leading some researchers to argue that it is "time to move on to other constructs that can better guide our understanding of achievement" (Huang, 2012, p.68).

\subsection{Explaining the inconsistent mastery goal-achievement relationship}

The fact that MGs are often weakly or unrelated to actual achievement highlights an important paradox in achievement goal research: Students who manifest the motivation to learn and to progress are not necessarily those who perform well. Why is this the case? Several explanations have been proposed for answering this intriguing question. A first explanation may lie in variations related to students' age, as a developmental trend seems to emerge in achievement goal research. Indeed, the MG-achievement relationship is more consistently found among elementary and middle school samples than among high school and college samples (see for reviews Linnenbrink-Garcia et al., 2008; Shim, Ryan, \& Anderson, 2008), although age or grade level have not emerged as significant moderators in meta-analytic work (Van Yperen, Blaga, \& Postmes, 2014; Wirthwein et al., 2013; see also Huang, 2012). A second explanation may be found in the use of different types of MG scales. As shown in meta-analytic work (Hulleman et al., 2010), the MG achievement link appears to be stronger when MG are measured without any reference to goal-relevant language (e.g., items referring to interest or affect). A third explanation is that students who pursue MGs have their own learning agenda that differs from the teachers' agenda, which may handicap them in some school contexts (Senko, Belmonte, \& Yakhkind, 2012; Senko, Hama, \& Belmonte, 2013; Senko \& Miles, 2008).

Despite their respective merits, all of these explanations rely on the implicit assumption that students' endorsement of achievement goals does exclusively reflect their true commitment with these goals. But does this assumption fit the social reality of most academic situations? What would be the consequences for interpreting the MG - achievement relation if this was an unwarranted assumption? In the next section we develop an approach that shows how such an assumption is problematic, since in many educational situations students endorse achievement goals, and especially MGs, not only because they truly pursue these goals, but also because they know they can use them as a self-presentation means to express some social value.

\subsection{Mastery goal endorsement in its social context: a social value approach}

According to recent research (Darnon, Dompnier, Delmas, Pulfrey, \& Butera, 2009) MGs are strongly promoted by teachers, and socially valued on the two fundamental dimensions of social judgment: Social desirability (or warmth) and social utility (or competence; Abele, Cuddy, Judd, \& Yzerbyt, 2008; Beauvois, 2003; Beauvois \& Dubois, 2009; Dubois \& Beauvois, 2005; Pansu \& Dompnier, 2011). According to Beauvois (2003), these two dimensions refer to two distinct facets of persons' social value. Social desirability denotes the individuals' capacity to satisfy the motivations of the members of a given social group and the degree to which they are liked by these group members. Social utility denotes the individuals' capacity to satisfy the functional constraints of a given social environment, and the degree to which they can succeed in this environment.

Using this social value framework to study achievement goal promotion at university, Darnon et al. (2009, study 1 ) showed that university students knew the positive consequences of MG endorsement on social judgment and were able to use this knowledge for selfpresentation purposes. Evidence for this was garnered with the self-presentation paradigm (Gilibert \& Cambon, 2003; Jellison \& Green, 1981; Ones \& Viswesvaran, 1998), with participants asked to respond to items of a MG scale (Elliot \& McGregor, 2001) according to different instructions: Standard, social desirability, and social utility. In the "standard" group, participants indicated their own level of agreement with each item (this condition corresponds to the standard instructions typically used in achievement goal research). In the "social desirability" group, they were asked to respond to the items as if they possessed all the qualities to make themselves likeable and popular with their teachers, that is, to use their knowledge of the construct's social desirability to serve self-presentation purposes. In the "social utility" group, they were asked to respond to the items as if they possessed all the qualities to succeed at university in the eyes of their teachers. Results revealed that students reported higher levels of MGs in the "social desirability" and "social utility" groups than in the "standard" group. ${ }^{2}$ These findings show that, on average, students can mobilize their knowledge of MGs' social value to align with what is socially valued in educational contexts (see Darnon et al., 2009, pilot study 1 ).

But does it mean that students actually use such knowledge when spontaneously answering a MG scale without any explicit selfpresentation instructions? One way to answer this question is to have a closer look at the context in which MGs are generally studied. Indeed, most of achievement goal research has been conducted in university or school contexts (Hulleman et al., 2010) and the educational system plays a central role in the distribution of social status in society (Darnon et al., 2012; Dornbusch, Glasgow, \& Lin, 1996). Thus, the typical class contexts in which individuals are generally asked to report their personal level of MG endorsement happen to be highly evaluative and could encourage (some) students to spontaneously adopt selfpresentation strategies. Indeed, it has been suggested that selfpresentation dynamics are operating in socially meaningful and evaluative contexts (e.g., Darnon et al., 2009; Egloff \& Schmukle, 2002; Rosse, Stecher, Miller, \& Levin, 1998). In other literatures, it is explicitly acknowledged that individuals self-present more favorably in public (as compared to private) contexts (see for instance s). In classrooms, teachers are physically and/or symbolically present, and are as such public, socially meaningful contexts.

In line with this reasoning, Dompnier, Darnon, and Butera (2009) argued that the MG - achievement link paradox may be explained by individual differences in these goals' perceived social value in educational contexts. More particularly, they argued that when students claim to pursue MGs, they may report endorsing these goals for at least two, non exclusive reasons: Because they truly pursue these goals - as assumed by classical achievement goal research - or because they want to be positively judged by the social agents in charge of the distribution of rewards in the university system, namely their teachers. Within this perspective, individual differences in students' perceptions of MGs' social desirability and social utility - as measured by the selfpresentation instructions - are conceived of as the reasons behind goal endorsement (Elliot, 2006; Elliot \& Thrash, 2001; Urdan \& Mestas, 2006; Vansteenkiste, Lens, Elliot, Soenens, \& Mouratidis, 2014) that influence their psychological meaning (Dompnier, Darnon, \& Butera, 2013). In other words, mastery goal endorsement on a self-report scale under standard instructions would not have the same meaning depending on the reasons why students report endorsing these goals, that is to be appreciated by their teachers (social desirability reasons) and to succeed in educational contexts from their teachers' perspective (social utility reasons). This conceptualization is in line with research on "goal complexes" (Elliot, 2006), which assumes that achievement goals may have different consequences depending on the reasons underlying their endorsement.

Consistent with hypotheses, Dompnier et al. (2009) demonstrated in a longitudinal study conducted on French psychology undergraduates that

\footnotetext{
2 Darnon et al. (2009) further demonstrated that performance-approach goals (i.e., trying to outperform others) were perceived as useful (high social utility), but not desirable (low social desirability). Performance-avoidance goals (i.e., trying not to perform more poorly than others) were instead perceived as desirable, but not useful. These findings indicate that students do not uniformly inflate their reported levels of achievement goals under self-presentation instructions, but that these levels align with the social value of each specific goal in educational contexts.
} 
the level of MG endorsement predicted academic performance at the end of an academic course, but only for those students who considered these goals to be highly useful for university success (i.e., high in social utility) and for those who did not perceive these goals as a means to garner their teachers' appreciation (i.e., low in social desirability). In other words, MGs' social value moderated the MG-achievement relationship, as it was facilitated by their level of social utility and inhibited by their level of social desirability. This would explain the counterintuitive, albeit frequent finding that MGs do not predict achievement.

\subsection{Mastery goals as a self-presentation strategy among adolescent students: a longitudinal study}

Following up on Dompnier et al.'s (2009) research on university undergraduates, one may wonder whether the moderating role of social desirability and social utility could be generalized to high school students, and with another type of achievement indicator. As Dompnier et al.'s (2009) research provides a critical view of the role of MGs in achievement-related settings, which may further support the claim that it is time to move on to other constructs to explain academic achievement (Huang, 2012), examining its replicability and generalizability is an important issue. Indeed, because peer influence is heightened during adolescence (e.g., Albert, Chein, \& Steinberg, 2013; Somerville, 2013), self-presentation strategies may not be primarily directed towards teachers, but instead towards peers. Dompnier et al.'s (2009) paradigm focusing on self-presentation strategies targeting teachers may therefore not be relevant for adolescents. If this is the case, there is no reason to expect a replication of the moderating role of social value on the MG - achievement relationship, and especially of the inhibiting role of social desirability. Alternatively, however, because MGs are highly valued by teachers in academic settings (Darnon et al., 2009) and students know they should report these goals to be valued, selfpresentation strategies targeting teachers may still be highly relevant, regardless of the importance of peer influence. If so, we ought to replicate the moderating role of MGs' social value at the high school level. To examine this issue, we designed a procedure that closely paralleled the one used by Dompnier et al. (2009), except for a noteworthy methodological improvement.

More particularly, contrary to Dompnier et al. (2009) who used students' grades at university, we developed, in collaboration with the school's teachers, two teacher-independent learning tests to assess students' learning and competence in a very important academic domain of the high school curriculum: French language. These tests were designed to assess skills that were part of the official learning program (e.g., text analysis, recognition of literature genres, stylistic devices; see http://www.vd.ch/fileadmin/user_upload/organisation/dfj/ dgep/dgvd/fichiers_pdf/PET_EM.pdf), which were taught at the onset of grade 10 and gradually consolidated. The tests were labeled teacherindependent learning tests because (i) each test item had an inherently correct answer, (ii) the correct answer could be objectively identified by an external grader (i.e., without relying on the grader's/teacher's subjective understanding of the answer), and (iii) the sum of all correct items provided a maximal performance indicator that functions as a standard. The reading materials (see Method section) were selected excerpts from books that were part of the high school exit exam, as defined by the Swiss Federal Program. ${ }^{3}$

The first test, administered during session 1, was used to control for individual differences in prior achievement. The second test, completed during session 2 , corresponded to our main performance measure. The use of teacher-independent learning tests, rather than exams graded by teachers, represents an important improvement, as the former are not biased by students' classroom behavior or other characteristics teachers are aware of and likely to influence their grading (see Ryan \&

\footnotetext{
3 The full list can be found at http://www.sbfi.admin.ch/themen/01366/01379/01626/ index.html?lang $=$ fr.
}

Ryan, 2005; Wirthwein et al., 2013). As an illustration, teachers' own grading of assignments and exams may favor students who are most likely to use MGs for self-presentation purposes, and particularly to garner teachers' appreciation (i.e., social desirability). This tendency can be inferred, for instance, from Dompnier et al.'s (2009) findings, as they show that, among students who did not strongly endorse MGs in the standard condition, those who nevertheless perceived these goals as highly desirable had a better grade than those who did not. In addition, meta-analytic findings show that the MG-achievement relation is weaker when the achievement outcome refers to teacher-independent test scores rather than to teacher-graded assessments (Wirthwein et al., 2013). In light of these results, examining the moderating role of individual differences in social value - and especially of social utility - represents an important issue in our understanding of which factors may contribute to this weaker relation.

\subsection{Hypotheses}

First, if high school students do indeed perceive MGs as a means to be appreciated by their teachers and to succeed in their French class, we should observe an increase of participants' level of MG endorsement in the social desirability and the social utility conditions compared to the standard condition (Hypothesis 1). Testing Hypothesis 1 is a crucial and mandatory first step as it tests whether MG are indeed socially valued among high school students, a point that cannot be inferred from previous research conducted at the university level (Darnon et al., 2009). If MG are indeed socially valued at the high school level, then we can expect the MG-achievement link to be inhibited by MG's level of social desirability (Hypothesis 2 ) and to be facilitated by their level of social utility (Hypothesis 3).

\section{Method}

\subsection{Participants}

Participants were 261 high-school students living in the French-speaking part of Switzerland. Only participants who were present for both testing session 1 and testing session 2 could be retained in final analyses. This criterion resulted in the exclusion of 51 participants (33 girls, 18 boys). Three additional participants were removed from the analyses because of an extreme Cook's distance or an uncommon studentized deleted residual (Judd \& McClelland, 1989) on reading comprehension performance. The final sample consisted of 207 participants (116 girls, 90 boys, 1 unreported; $M_{\text {age }}=17, S D=$ $1.64 ; 91$ 10th graders, 5311 th graders, and 6312 th graders). Additional demographic information regarding the final sample is provided as online supplementary materials.

\subsection{Measures}

\subsubsection{Designing the reading comprehension measures}

The main requirement when designing the learning measures was to assess skills that were part of the official learning program (e.g., text analysis, recognition of literature genres, stylistic devices), as these were taught at the onset of grade 10 and gradually consolidated. The content of the tests was therefore first discussed between the teacher and researchers, who subsequently interacted on a regular basis to construct the tests, and teachers finally validated that the tests assessed skills targeted by the program. Tests were thus designed to assess learning and skill acquisition, with the type of questions used (i.e., bridging and elaborative inference questions) known to tap in learning processes (McNamara, Kintsch, Songer, \& Kintsch, 1996). We equated the two tests in terms of types and numbers of questions, to ensure that they assessed the acquisition of the same concepts. Test 1 scores were only used to control for individual differences in prior 
achievement (i.e., covariate function), with scores on the second test corresponding to our main performance measure.

\subsubsection{Initial level of competence in French language reading comprehension} measure (test 1)

This test consisted in reading an excerpt from a literature book (André Malraux, "La condition humaine" [Human condition]) and in answering 10 multiple-choice questions (each including a set of four options) related to the excerpt. Questions did not require verbatim memory of the reading material, but instead some degree of processing of text content, as well as prior knowledge (see Appendix A). More precisely, following McNamara et al.'s (1996) work, six questions were classified as elaborative inference questions (i.e., text information and outside knowledge had to be linked to answer the question), and four as bridging inference questions (i.e., information is provided in the text but requires linking two or more sentences). A mean comprehension score was computed for each participant by assigning 1 point for each correct answer and 0 otherwise, resulting in a score ranging from 0 to 10 .

\subsubsection{Final level of competence in french language reading comprehension measure (test 2)}

This test consisted in reading an excerpt from another literature book (Michel de Montaigne, "De l'amitié"[About friendship]) and in answering 10 multiple-choice questions related to this new excerpt. Characteristics of this second test were comparable to those of test 1 , in terms of testing conditions, testing time, type of questions (six questions were classified as elaborative inference questions, and four as bridging inference questions; see Appendix A for examples), multiplechoice format (i.e., four options), and scoring procedure (scores ranging from 0 to 10).

\subsubsection{Mastery-approach goal scale}

This measure comprised three items inviting participants to rate the extent to which their aim in their French class was "to learn as much as possible," "to understand what is taught," and "to master what is taught." Participants provided ratings on a 7-point scale $(1=$ not at all true for me; $7=$ very true for me). These items corresponded to French version of the mastery-approach subscale of Elliot and McGregor's (2001) achievement-goal scale. This French version has been validated by Darnon and Butera (2005), who reported that the scale had good internal consistency ( $\alpha=.84$ ), and was positively related to deep learning strategies and intrinsic motivation. In the present research, internal consistency indicators for the mastery-approach goal scale were also good under standard instructions ( $\alpha=.75$ ), social-desirability instructions ( $\alpha=.83)$, and social-utility instructions $(\alpha=.80)$.

\subsubsection{Demographic information}

The demographic section comprised items about participants' age, school grade (10th, 11th, or 12th), gender, and parental educational attainment (mother's and father's highest degree).

\subsubsection{Technical adequacy of the reading comprehension measures}

Means, standard deviations, and correlations for all measures are displayed in Table 1. Of particular interest regarding the reliability and validity of the reading comprehension measures are the significant positive correlations between session 1 and 2 test scores $(r=.36$, $p<.01$ ). Additional analyses, testing the impact of students' grade level on session 1 and 2 test scores, are provided as online Supplementary materials.

\subsection{Procedure}

The two waves of data collection took place at the beginning and at the end of the spring semester in the same high school, with the informed participation of both the headmaster and the teachers. The research was introduced as a study on students' motivations in French
Table 1

Mean values of the study's measures (and standard deviations) and their intercorrelations.

\begin{tabular}{|c|c|c|c|c|c|c|c|}
\hline \multirow[b]{2}{*}{ Measures } & \multirow[t]{2}{*}{ Mean } & \multirow{2}{*}{$\begin{array}{l}\text { Standard } \\
\text { deviations }\end{array}$} & \multicolumn{5}{|c|}{ Correlations } \\
\hline & & & 1 & 2 & 3 & 4 & 5 \\
\hline $\begin{array}{l}\text { 1. Mastery goal endorsement } \\
\text { (standard condition) }\end{array}$ & 4.59 & 1.13 & - & & & & \\
\hline $\begin{array}{l}\text { 2. Social desirability of } \\
\text { mastery goal }\end{array}$ & 5.93 & .93 & $.21^{* *}$ & - & & & \\
\hline 3. Social utility of mastery goal & 6.63 & .64 & $.19^{* *}$ & $.37^{* *}$ & - & & \\
\hline 4. Test 1 & 4.94 & 1.65 & -.02 & $.17^{*}$ & $.20^{* *}$ & - & \\
\hline 5. Test 2 & 6.19 & 1.84 & .02 & -.03 & .04 & $.36^{* *}$ & - \\
\hline
\end{tabular}

* $p<.05$.

** $p<.01$.

language and only participants who received parental consent took part in the study. All sessions were run in groups during a regular class hour.

During session 1, participants first completed the test measuring their initial level of competence in French language reading comprehension. Testing time was limited to $17 \mathrm{~min}$ and all participants had finished the test before this time limit had elapsed. They subsequently filled out a questionnaire comprising the mastery-approach goal items. As in Dompnier et al. (2009), participants completed the mastery-approach goal items three times - first in the standard condition and then according to two within-participants conditions (social desirability and social utility, order counterbalanced). In the standard condition, participants indicated their own level of agreement with each item. In the social-desirability condition, instructions were as follows: "Indicate your level of agreement with each of the following statements, with a view to presenting yourself as someone who is likely to be appreciated by your teachers". In the social-utility condition, instructions stated: "Indicate your level of agreement with each of the following statements, with a view to presenting yourself as someone who is likely to succeed in his or her studies". The standard version was always presented first to obtain an uncontaminated measure of students' a priori endorsement of MGs; order of the social desirability and social-utility instructions was counterbalanced across participants. Participants finally completed the demographic information.

Four months after participating in session 1, students took part in session 2, again during a regular class hour. The procedure for this second session closely paralleled that used in session 1. Participants first completed a test measuring the final level of competence in French language reading comprehension and subsequently filled out some additional measures, which were not related to the present study's hypotheses. Participants were then thanked and debriefed.

\subsection{Data analysis}

\subsubsection{Regression model}

A regression model estimated with generalized least squares (GLS) was used to test hypotheses regarding the predicted interactions between MG endorsement in the standard condition and perception of this goal's social desirability (Hypothesis 2) and social utility (Hypothesis 3) on session 2's test scores. This model included session 1 's test scores, MG endorsement in the standard condition, MG endorsements in the social desirability and social utility conditions, and interaction products among these variables as predictors (six two-way interactions, four three-way interactions, and one four-way interaction; see Judd \& McClelland, 1989). All the fifteen predictors (i.e., the four predictors plus all the two-, three-, and four-way interactions) were mean-centered. Assumptions of regression analysis, along with a thorough description of the analytical rationale, are provided as online supplementary materials. 


\section{Results}

\subsection{The social value of mastery goals at high school level (Hypothesis 1)}

Before testing our main hypotheses, a first and necessary step was to show that indeed high school students perceived MGs as a means to be appreciated by their teachers and as a means to succeed in their French class. If this is true, we should observe an increase of participants' level of MG endorsement in the social desirability and the social utility conditions compared to the standard condition (Hypothesis 1 ). In order to test this precondition, a within participants analysis of variance was conducted on the data. More particularly, the three conditions (i.e., standard, social desirability, and social utility conditions) were compared using two orthogonal contrasts (Helmert coding): While the first contrast opposed the standard condition (coded -2 ) to the social desirability and social utility conditions (each coded 1), the second contrast opposed the social desirability condition (coded -1 ) and the social utility condition (coded 1) and excluded the standard condition (coded 0) from this comparison. This specific set of contrasts allows a direct comparison between the standard and the two self-presentation conditions (contrast 1 ), as well as between the two self-presentation conditions (contrast 2; e.g., Judd \& McClelland, 1989).

As shown by Table 1 , results revealed that mean scores in the standard condition $(M=4.59, S D=1.13)$ were lower than in the social desirability $(M=5.93, S D=.93)$ and social utility $(M=6.63, S D=.64)$ conditions (test of a contrast 1$), F(1,206)=438.36, p<.001, \eta_{p}^{2}=.68$. This suggests, as expected, that MGs are highly socially valued at the high school level on the two dimensions of social value and that high school students are able to use these goals for self-presentation purposes. In addition, the results revealed that mean scores in the social desirability condition were lower than in the social utility condition (test of contrast 2$), F(1,206)=122.67, p<.001, \eta_{p}^{2}=.37$. Thus, even if MGs are highly valued on the two dimensions of social value, high school students perceived these goals as more socially useful than socially desirable.

\subsection{Moderation analyses for learning performance in French (Hypotheses 2} and 3)

We first regressed session 2's test scores on the 15 terms of the model (i.e., the four predictors plus all the two-, three-, and four-way interactions). The regression analysis revealed a main effect of session 1 's test scores, $b=0.37, F(1,191)=19.88, p<.001, \eta_{p}^{2}=.09$, and a main effect of perception of MGs' social desirability, $b=-0.33$, $F(1,191)=4.25, p<.05, \eta_{p}^{2}=.02$. More importantly, and as expected (Hypothesis 2), this effect was qualified by an interaction effect between MG endorsement in the standard condition and perception of this goal's social desirability, $b=-0.27, F(1,191)=3.94, p<.05$, $\eta_{p}^{2}=.02$. As illustrated in Fig. 1, the relationship between MG endorsement in the standard condition and test scores was more positive at a low level (i.e., at a value of 5.07, which corresponds to one variance below the mean), than at a high level of perceived social desirability (i.e., at a value of 6.79 , which corresponds to one variance above the mean).

Finally, results revealed that the expected interaction effect between MG endorsement in the standard condition and perception of these goals' social utility (Hypothesis 3 ) was significant, $b=0.53, F(1$, $191)=5.35, p<.05, \eta_{p}^{2}=.03$. As can be seen in Fig. 2, the relationship between MG endorsement in the standard condition and test scores was more positive at a high (i.e., at a value of 7 , which corresponds to one variance above the mean) than at a low level of perceived social utility (i.e., at a value of 6.22 , which corresponds to one variance below the mean). No other main or interaction effects were found (all Fs < 1.56). Results for the full regression model can be found in Table 2.

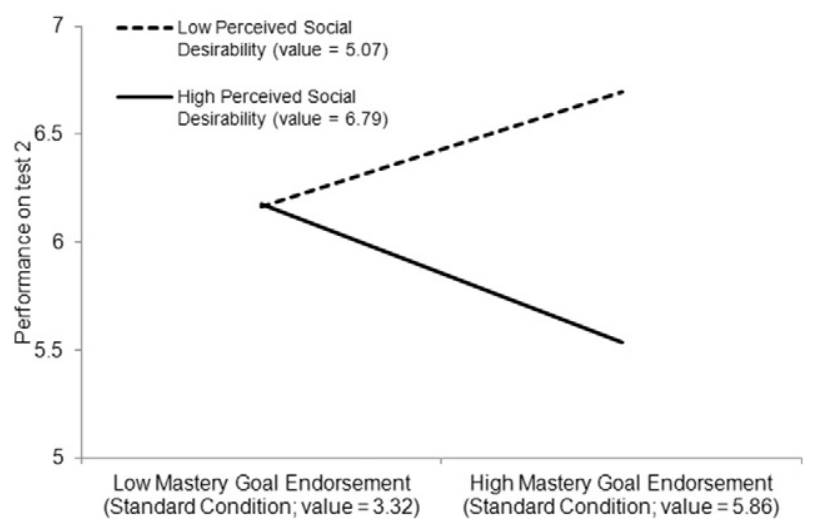

Fig. 1. Performance on test 2 as a function of mastery goal endorsement (standard condition) and mastery goal's perceived social desirability (numerical values correspond to plus or minus one variance around the mean).

\section{Discussion}

The aim of the present research was to test whether the moderating role of social desirability and social utility on the MG - achievement relationship (see Dompnier et al., 2009) could be replicated and generalized to students who are younger than university students, who are studying in a different educational context than university, and who are completing externally-graded (instead of teacher-graded) achievement measures.

First, consistent with the assumption that MGs are valued at the high school level, findings indicate that high school students were able to adapt their level of MG endorsement as a function of their selfpresentational concerns, as means in the social desirability and social utility conditions were higher than in the standard condition (Hypothesis 1). Thus, high school students know that expressing MGs to a larger extent may help them to be appreciated by teachers and to succeed at school. Second, findings support the relevance of a social value approach to understand the MG - achievement relationship at the high school level. Indeed, as shown at the university level (Dompnier et al., 2009), this relationship was inhibited by MGs' level of social desirability (Hypothesis 2) and facilitated by their level of social utility (Hypothesis 3 ).

The present research, by extending previous findings (Dompnier et al., 2009) to a sample of adolescent students, in a high school context, and with the use of teacher-independent, externally-graded learning

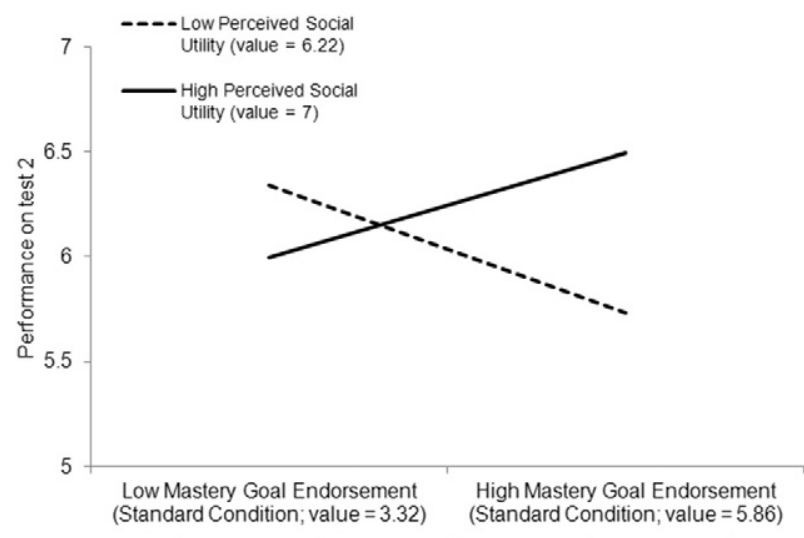

Fig. 2. Performance on test 2 as a function of mastery goal endorsement (standard condition) and mastery goal's perceived social utility (numerical values correspond to plus or minus one variance around the mean). 
Table 2

Regression analysis predicting performance on test 2 .

\begin{tabular}{lrrrl}
\hline Predictors & \multicolumn{1}{l}{$b$} & \multicolumn{1}{l}{ SE } & \multicolumn{1}{l}{ F } \\
\hline Initial Performance (IP) & .37 & .08 & 19.88 & .001 \\
Mastery Goal Endorsement (MGE) & -.02 & .13 & .03 & .86 \\
Mastery Goals' Social Desirability (MGSD) & -.33 & .16 & 4.25 & .04 \\
Mastery Goals' Social Utility (MGSU) & .25 & .27 & .88 & .35 \\
MGE $\times$ MGSD & -.27 & .14 & 3.94 & .05 \\
MGE $\times$ MGSU & .53 & .23 & 5.35 & .02 \\
MDSD $\times$ MDSU & .30 & .30 & 1.03 & .31 \\
MGE $\times$ IP & .05 & .08 & .23 & .59 \\
MGSD $\times$ IP & .03 & .10 & .11 & .74 \\
MGSU $\times$ IP & .07 & .18 & .14 & .71 \\
MGE $\times$ MGSD $\times$ MGSU & .40 & .32 & 1.55 & .21 \\
MGE $\times$ MGSD $\times$ IP & -.07 & .08 & .69 & .41 \\
MGE $\times$ MGSU $\times$ IP & .06 & .17 & .12 & .73 \\
MGSD $\times$ MGSU $\times$ IP & .16 & .16 & .95 & .33 \\
MGE $\times$ MDSD $\times$ MGSU $\times$ IP & .07 & .16 & .22 & .64 \\
\hline
\end{tabular}

tests, strengthens the general hypothesis that students endorse MGs not only because they truly pursue these goals, but also because they use them as a means to express some social value. The present study therefore fulfills the important goal of providing a conceptual replication, while also providing theoretical and empirical support for reconsidering an implicit assumption of achievement goal theory, namely, that students' endorsement of achievement goals does exclusively reflect their true commitment with these goals. Although it would prove difficult to determine to what extent this social value component might have been present in previous studies, as the use of self-presentation strategies is highly context-dependent (Egloff \& Schmukle, 2002) and thus also highly dependent on teachers as they strongly contribute to create situational constraints (e.g., Ames, 1992; Urdan \& Schoenfelder, 2006), exploring this issue, possibly at the meta-analytical level, would be an important avenue for future research.

Given the correlational nature of the present research and that of Dompnier et al. (2009), other interpretations than those guided by the social value approach may be warranted. However, recent experimental findings (Dompnier et al., 2015) demonstrate that (self-reported) MG endorsement is related to achievement, but only in a manipulated high social utility/neutral social desirability condition. In other words, this work provides experimental evidence that social value has causal influence on the MG-achievement relation. Additionally, to provide convergent validity to the present social value approach another avenue would be to use behavioral indicators of goal orientation, such as goal traces (Zhou \& Winne, 2012), which are less affected by self-presentation strategies than self-reports. Beyond the educational realm, the present work may also offer relevant perspectives for research targeting other situations where self-presentation concerns are high (e.g., job interviews) and the use of self-report measures (e.g., personality scales) is extensive (e.g., Griffith \& Peterson, 2011; Uziel, 2010).

To conclude, the present research provides convergent evidence that in educational settings - such as high schools - adolescents' endorsement of MGs may reflect their true commitment with these goals only for some of them, and also serve a self-presentation strategy for others. These individual differences may be worthwhile taking into account when assessing adolescent students' academic motivation, learning, and performance. It also suggests that educational interventions based on the present results may be developed to sustain adolescent students' motivation to learn, as MGs are positively related to achievement, provided that the moderating roles of social utility and social desirability are taken into account. In other words, it may be beneficial for educators or parents who would like to promote MGs and achievement to additionally convey the notion that MGs are actually useful to learn (high social utility) but not the notion that their expression may also increase teachers' appreciation (low social desirability).

\section{Appendix A}

Examples of test 1 multiple-choice questions:

What is the literature genre of this text? (Elaborative inference question)
a) Fable
b) Essay
c) Philosophical tale
d) Novel

In this text, which distinctive feature allows identifying the literature genre? (Elaborative inference question)
a) The moral
b) The text in prose
c) The characters, for whom the author emphasizes their destiny
d) b) and c)

Through Gisors, the author makes a contrasted portrait of two... (Bridging inference question)

a) Persons in their seventies

b) Revolutionary-inclined persons

c) Mercenaries

d) Ordinary persons

To describe Kyo's constancy and coherence, the author relies on... (Bridging inference question)
a) Negations between words
b) Oppositions between words
c) Repetition between words
d) Balance between words

Examples of test 2 multiple-choice questions:

What is the literature genre of this text? (Elaborative inference question)
a) Fable
b) Essay
c) Philosophical tale
d) Theater

In this text, which distinctive feature allows identifying the literature genre? (Elaborative inference question)
a) The author's subjective viewpoint
b) The moral
c) The argumentative structure
d) a) and c)

The author contrasts his friendship with La Boétie with friendships that are more... (Bridging inference question)
a) Audacious
b) Spectacular
c) Gregarious
d) Ordinary

According to the author, the friendship between him and La Boétie is definitely... (Bridging inference question)
a) Equivocal
b) Reciprocal
c) Zany
d) Baroque 


\section{Appendix B. Supplementary data}

Supplementary data to this article can be found online at http://dx. doi.org/10.1016/j.lindif.2015.08.036.

\section{References}

Abele, A. E., Cuddy, A. J. C., Judd, C. M., \& Yzerbyt, V. (2008). Fundamental dimensions of social judgment. European Journal of Social Psychology, 38, 1063-1065. http://dx.doi. org/10.1002/ejsp.574.

Albert, D., Chein, J., \& Steinberg, L. (2013). The teenage brain: Peer influences on adolescent decision making. Current Directions in Psychological Science, 22, 114-120. http://dx.doi. org/10.1177/0963721412471347.

Ames, C. (1992). Classrooms: Goals, structure, and student motivation. Journal of Educational Psychology, 84, 261-271. http://dx.doi.org/10.1037/0022-0663.84.3.261.

Beauvois, J. L. (2003). Judgment norms, social utility, and individualism. In N. Dubois (Ed.), A sociocognitive approach to social norms (pp. 123-147). London: Routledge.

Beauvois, J. L., \& Dubois, N. (2009). Lay psychology and the social value of persons. Social and Personality Psychology Compass, 3, 1082-1095. http://dx.doi.org/10.1111/j.17519004.2009.00225.x.

Darnon, C., \& Butera, F. (2005). Buts d'accomplissement, stratégies d'étude et motivation intrinsèque: Présentation d'un domaine de recherche et validation française de l'échelle d'Elliot et MacGregor (2001). [Achievement goals, study strategies, and intrinsic motivation: Presenting a domain of research and the French validation of Elliot \& McGregor's (2001) scale]. L'Année Psychologique, 105, 105-131. http://dx. doi.org/10.3406/psy.2005.3821.

Darnon, C., Dompnier, B., Delmas, F., Pulfrey, C., \& Butera, F. (2009). Achievement goal promotion at University: Social desirability and social utility of mastery and performance goals. Journal of Personality and Social Psychology, 96, 119-134. http://dx.doi.org/10.1037/ a0012824.

Darnon, C., Dompnier, B., \& Poortvliet, P. M. (2012). Achievement goals in educational contexts: A social psychology perspective. Social and Personality Psychology Compass, 6, 760-771. http://dx.doi.org/10.1111/j.1751-9004.2012.00457.x.

Dompnier, B., Darnon, C., \& Butera, F. (2009). Faking the desire to learn: A clarification of the link between mastery goals and academic achievement. Psychological Science, 20 939-943. http://dx.doi.org/10.1111/j.1467-9280.2009.02384.x.

Dompnier, B., Darnon, C., \& Butera, F. (2013). When performance-approach goals predict academic achievement and when they do not: A social value approach. British Journal of Social Psychology, 52, 587-596. http://dx.doi.org/10.1111/bjso.12025.

Dompnier, B., Darnon, C., Meier, E., Brandner, C., Smeding, A., \& Butera, F. (2015). Improving low achievers' academic performance by changing the social value of mastery goals. American Educational Research Journal, 52, 720-749. http://dx.doi.org/10. 3102/0002831215585137.

Dubois, N., \& Beauvois, J. L. (2005). Normativeness and individualism. European Journal of Social Psychology, 35, 123-146. http://dx.doi.org/10.1002/ejsp.236.

Dornbusch, S. M., Glasgow, K. L., \& Lin, I. C. (1996). The social structure of schooling. Annual Review of Psychology, 47, 401-429. http://dx.doi.org/10.1146/annurev.psych. 47.1.401.

Dweck, C. S., \& Leggett, E. L. (1988). A social-cognitive approach to motivation and personality. Psychological Review, 95, 256-273. http://dx.doi.org/10.1037/0033295X.95.2.256.

Egloff, B., \& Schmukle, S. C. (2002). Predictive validity of an implicit association test for assessing anxiety. Journal of Personality and Social Psychology, 83, 1441-1455. http:// dx.doi.org/10.1037//0022-3514.83.6.1441.

Elliot, A. J. (1999). Approach and avoidance motivation and achievement goals. Educational Psychologist, 34, 169-189. http://dx.doi.org/10.1207/s15326985ep3403_3.

Elliot, A. J. (2006). The hierarchical model of approach-avoidance motivation. Motivation and Emotion, 30, 111-116. http://dx.doi.org/10.1007/s11031-006-9028-7.

Elliot, A. J., \& McGregor, H. A. (2001). A $2 * 2$ achievement goal framework. Journal of Personality and Social Psychology, 80, 501-519. http://dx.doi.org/10.1037/0022-3514. 80.3.501.

Elliot, A. J., \& Murayama, K. (2008). On the measurement of achievement goals: Critique, illustration, and application. Journal of Educational Psychology, 100, 613-628. http:// dx.doi.org/10.1037/0022-0663.100.3.613.

Elliot, A. J., \& Thrash, T. M. (2001). Achievement goals and the hierarchical model of achievement motivation. Educational Psychology Review, 13, 139-156 (doi:1040726X/01/0600-0139\$19.50/0).

Gilibert, D., \& Cambon, L. (2003). Paradigms of the sociocognitive approach. In N. Dubois (Ed.), A sociocognitive approach to social norms (pp. 38-69). London: Routledge.

Griffith, R. L., \& Peterson, M. H. (2011). One piece at a time: The puzzle of applicant faking and a call for theory. Human Performance, 24, 291-301. http://dx.doi.org/10.1080/ 08959285.2011.597474.

Harackiewicz, J. M., Barron, K. E., Pintrich, P. R., Elliot, A. J., \& Thrash, T. M. (2002). Revision of achievement goal theory: Necessary and illuminating. Journal of Educational Psychology, 94, 638-645. http://dx.doi.org/10.1037/0022-0663.94.3.638.
Huang, C. (2012). Discriminant and criterion-related validity of achievement goals in predicting academic achievement: A meta-analysis. Journal of Educational Psychology, 104, 48-73. http://dx.doi.org/10.1037/a0026223.

Hulleman, C. S., Schrager, S. M., Bodmann, S. M., \& Harackiewicz, J. M. (2010). A metaanalytic review of achievement goal measures: Different labels for the same constructs or different constructs with similar labels. Psychological Bulletin, 136, 422-449. http://dx. doi.org/10.1037/a0018947.

Jellison, J. M. \& Green, J. (1981). A self-presentation approach to the fundamental attribution error: The norm of internality. Journal of Personality and Social Psychology, 40, 643. http://dx.doi.org/10.1037/0022-3514.40.4.643.

Judd, C. M., \& McClelland, G. H. (1989). Data analysis: A model comparison approach. San Diego: Harcourt, Brace, Jovanovich.

Linnenbrink-Garcia, L., Tyson, D. F., \& Patall, E. A. (2008). When are achievement goals orientations beneficial for academic achievement? A closer look at main effects and moderating factors. International Review of Social Psychology, 21, 19-70.

McNamara, D. S., Kintsch, E., Songer, N. B., \& Kintsch, W. (1996). Are good texts always better? Interactions of text coherence, background knowledge, and levels of understanding in learning from text. Cognition and Instruction, 14, 1-43. http://dx.doi. org/10.1207/s1532690xci1401_1.

Nicholls, J. G. (1984). Achievement motivation: Conceptions of ability, subjective experience task choice, and performance. Psychological Review, 91, 328-346. http://dx.doi.org/10. 1037/0033-295X.91.3.328.

Ones, D. S., \& Viswesvaran, C. (1998). The effects of social desirability and faking on personality and integrity assessment for personnel selection. Human Performance, 11, 245-269. http://dx.doi.org/10.1080/08959285.1998.9668033.

Pansu, P., \& Dompnier, B. (2011). A bidimensional scale of scholastic value: Social desirability and social utility, two dimensions of personological judgment. European Review of Applied Psychology, 61, 31-41. http://dx.doi.org/10.1016/j.erap.2010.08.001.

Poortvliet, P. M. \& Darnon, C. (2010). Towards a more social understanding of achievement goals: The interpersonal effects of mastery and performance goals. Current Directions in Psychological Science, 19, 324-328. http://dx.doi.org/10.1177/0963721410383246.

Rosse, J. G., Stecher, M. D., Miller, J. L., \& Levin, R. A. (1998). The impact of response distortion on preemployment personality testing and hiring decisions. Journal of Applied Psychology, 83, 634-644. http://dx.doi.org/10.1037/0021-9010.83.4.634.

Ryan, K. E., \& Ryan, A. M. (2005). The psychological processes underlying stereotype threat and standardized math test performance. Educational Psychologist, 40, 53-63. http:// dx.doi.org/10.1207/s15326985ep4001_4.

Senko, C., Belmonte, K., \& Yakhkind, A. (2012). How students' achievement goals shape their beliefs about effective teaching: A "Build-A-Professor" study. British Journal of Educational Psychology, 82, 420-435. http://dx.doi.org/10.1111/j.2044-8279.2011. 02036.x.

Senko, C., Hama, H., \& Belmonte, K. (2013). Achievement goals, study strategies, and achievement. A test of the "learning agenda" framework. Learning and Individual Differences, 24, 1-10. http://dx.doi.org/10.1016/j.lindif.2012.11.003.

Senko, C., Hulleman, C. S., \& Harackiewicz, J. M. (2011). Achievement goal theory at the crossroads: Old controversies, current challenges, and new directions. Educational Psychologist, 46, 26-47. http://dx.doi.org/10.1080/00461520.2011.538646.

Senko, C., \& Miles, K. M. (2008). Pursuing their own learning agenda: How masteryoriented students jeopardize their exam performance. Contemporary Educationa Psychology, 33, 561-583. http://dx.doi.org/10.1016/j.cedpsych.2007.12.001.

Shim, S. S., Ryan, A. M., \& Anderson, C. J. (2008). Achievement goals and achievement during early adolescence: Examining time-varying predictor and outcome variables in growth-curve analysis. Journal of Educational Psychology, 100, 655-671. http://dx.doi. org/10.1037/0022-0663.100.3.655.

Somerville, L. H. (2013). The teenage brain: Sensitivity to social evaluation. Current Directions in Psychological Science, 22, 121-127. http://dx.doi.org/10.1177/0963721413476512.

Urdan, T., \& Mestas, M. (2006). The goals behind performance goals. Journal of Educational Psychology, 98, 354-365. http://dx.doi.org/10.1037/0022-0663.98.2.354.

Urdan, T., \& Schoenfelder, E. (2006). Classroom effects on student motivation: Goal structures, social relationships, and competence beliefs. Journal of School Psychology, 44, 331-349. http://dx.doi.org/10.1016/j.jsp.2006.04.003.

Uziel, L. (2010). Rethinking social desirability scales: From impression management to interpersonally oriented self-control. Perspectives on Psychological Science, 5, 243-262. http://dx.doi.org/10.1177/1745691610369465.

Vansteenkiste, M., Lens, W., Elliot, A. J., Soenens, B., \& Mouratidis, A. (2014). Moving the achievement goal approach one step forward: Toward a systematic examination of the autonomous and controlled reasons underlying achievement goals. Educational Psychologist, 49, 153-174. http://dx.doi.org/10.1080/00461520.2014.928598.

Van Yperen, N. W., Blaga, M., \& Postmes, T. (2014). A meta-analysis of self-reported achievement goals and nonself-report performance across three achievement domains (work, sports, and education). PloS One, 9(4), e93594.

Wirthwein, L., Sparfeldt, J. R., Pinquart, M., Wegerer, J., \& Steinmayr, R. (2013). Achievement goals and academic achievement: A closer look at moderating factors. Educational Research Review, 10, 66-89. http://dx.doi.org/10.1016/j.edurev.2013.07.001.

Zhou, M., \& Winne, P. H. (2012). Modeling academic achievement by self-reported versus traced goal orientation. Learning and Instruction, 22, 413-419. http://dx.doi.org/10. 1016/j.learninstruc.2012.03.004. 